\title{
Rancang Bangun Decision Support System (DSS) untuk Membantu Menentukan Hasil Seleksi Pegawai pada Politeknik Negeri Cilacap dengan Menggunakan Metode Perbandingan Eksponensial (MPE)
}

\author{
Riyadi Purwanto* \\ Jurusan Teknik Informatika, Politeknik Negeri Cilacap, Cilacap \\ Jln. Dr. Soetomo, No.1 Sidakaya Cilacap, 537992, Indonesia \\ email: adidok_bayu@yahoo.com
}

Received: 28 Maret 2018; Revised: 8 Mei 2018; Accepted: 13 Mei 2018

Copyright $@ 2018$ Politeknik Harapan Bersama Tegal. All rights reserved

\begin{abstract}
Information Technology has provided an important role as a communication medium to support the business processes of industry / companies, government agencies, and educational institutions. One form of utilization of information technology is as a media Decision support system (DSS) that can be used to assist decision-making for a leader. Decision Support System (DSS) is an interactive information system that provides information, modeling, and data manipulation. The system is used to assist decision making in semi-structured situations and structured situations, where nobody knows exactly how decisions should be made. At this time the process of employee selection on the PNC is still done conventionally, causing several problems, among others: $\left.{ }^{1}\right)$ Often miscalculated value skors, $\left.{ }^{2}\right)$ Factors like and dislike very high, ${ }^{3}$ )Sometimes the leadership has difficulty when determining the right employee to be accepted based on predetermined criteria. Looking at the existing problems, it is necessary to develop Decision Support System (Decision Support System) that can help the leadership of Cilacap State Polytechnic to determine the result of new Employee selection in Cilacap State Polytechnic environment based on predetermined criteria. The system was developed using the Exponential Comparison Method (MPE) ". The assessment standards used include: completeness of administrative documents, Skor of Basic Field, English Test, Competence Testing of Theory Field, Competence Test of Practice Field, and interview test which is given the weight of each value. Assessment results are sorted from the highest to the lowest. With this system, the decisions that the leader's lead becomes appropriate and potential.
\end{abstract}

Abstrak - Teknologi Informasi telah memberikan peran penting sebagai media komunikasi untuk mendukung proses bisnis industri/perusahaan, instansi pemerintah, maupun institusi pendidikan. Salah satu bentuk

*) Corresponding author: Riyadi Purwanto

Email: adidok_bayu@yahoo.com pemanfaatan teknologi informasi yaitu sebagai media Decision support system (DSS) yang dapat digunakan untuk membantu pengambilan keputusan bagi seorang pimpinan. Decision Support System (DSS) merupakan sistem informasi interaktif yang menyediakan informasi, pemodelan, dan pemanipulasian data. Sistem itu digunakan untuk membantu pengambilan keputusan dalam situasi yang semi terstruktur dan situasi yang terstruktur, dimana tak seorangpun tahu secara pasti bagaimana keputusan seharusnya dibuat. Pada saat ini proses seleksi pegawai pada PNC masih dilakukan secara konvensional, sehingga menyebabkan beberapa masalah antara lain : ${ }^{1}$ )Sering terjadi kesalahan perhitungan skor nilai, ${ }^{2}$ )Faktor like and dislike sangat tinggi, ${ }^{3}$ )Terkadang pimpinan mengalami kesulitan pada saat menentukan pegawai yang tepat untuk diterima berdasarkan kriteriakriteria yang telah ditentukan. Melihat permasalahan yang ada, maka perlu dikembangkan Sistem Pendukung Keputusan (Decision Support System) yang dapat membantu pimpinan Politeknik Negeri Cilacap untuk menentukan hasil seleksi Pegawai baru di lingkungan Politeknik Negeri Cilacap dengan berdasarkan pada kriteria-kriteria yang telah ditentukan. Sistem dikembangkan dengan menggunakan Metode Perbandingan Eksponensial (MPE)". Standar penilaian yang digunakan antara lain : kelengkapan dokumen administrasi, Skor nilai Tes Kemampuan Dasar, Tes Bahasa Inggris, Tes Kompetensi Bidang Teori, Tes Kompetensi Bidang Praktek, dan Tes Wawancara yang diberi bobot nilai masing-masing. Hasil penilaian diurutkan dari nilai tertinggi ke nilai terendah. Dengan adanya sistem ini keputusan yang diambil pimpinan menjadi tepat dan potensial.

Kata Kunci: Seleksi Pegawai, Sistem Pendukung Keputusan, Metode Perbandingan Eksponensial

\section{PENDAHULUAN}

Teknologi Informasi telah memberikan peran penting sebagai media komunikasi untuk mendukung proses bisnis 
industri/perusahaan, instansi pemerintah, maupun institusi pendidikan. Salah satu bentuk pemanfaatan teknologi informasi yaitu sebagai media Decision support sistem (DSS) yang dapat membantu proses pengambilan keputusan. Untuk menentukan keputusan yang bersifat kompleks pengambil keputusan akan memerlukan bantuan/tools dalam bentuk analisis yang bersifat ilmiah, terstruktur dan konsisten berguna untuk menguatkan keyakinan terhadap alternatif yang dipilih. Salah satu alat analisis untuk membantu menentukan keputusan tersebut adalah decision making model (Model Pembuat Keputusan)[1]. Decision Support System adalah sistem berbasis komputer yang menyajikan dan memproses informasi yang memungkinkan pembuatan keputusan menjadi lebih produktif, dinamis dan inovatif [2].

Politeknik Negeri Negeri Cilacap merupakan salah satu Perguruan Tinggi Negeri dibawah Kementrian Riset Teknologi dan Pendidikan Tinggi. Perguruan Tinggi adalah sebuah organisasi dengan kumpulan aktivitas atau pekerjaan terstruktur yang saling terkait untuk menghasilkan lulusan, karya akademik Dosen, penelitian dan pengabdian[3]. Politeknik Negeri Cilacap beralamat di Jl. Dr. Soetomo, No.1 Sidakaya Cilacap, Jawa Tengah. Saat ini Politeknik Negeri Cilacap telah menyelenggarakan 7 (tujuh) Program Studi dan memiliki 734 mahasiswa aktif. Jumlah pegawai Politeknik Negeri Cilacap sebanyak 106 yang terdiri dari 32 Tenaga Pendidik dan 74 Tenaga Kependidikan.

Seiring dengan bertambahnya Program Studi dan pertumbuhan jumlah mahasiswa yang terus meningkat berdampak pada kebutuhan pegawai baik Dosen maupun Tenaga Kependidikan. Dosen memiliki peranan penting dalam transformasi keilmuan kepada mahasiswa yang mempengaruhi hasil prestasi belajar mahasiswa[4]. Sedangkan Tenaga Kependidikan sebagai Sumber Daya Penunjang penyelenggaraan pendidikan untuk mencapai tujuan yaitu menghasilkan lulusan yang berkualitas[5].

Pada saat ini proses seleksi pegawai pada PNC masih dilakukan secara konvensional. Perhitungan bobot dan skor nilai hasil ujian atau seleksi pada setiap tahap masih dilakukan secara manual. Hal ini menimbulkan beberapa permasalahan, antara lain : ${ }^{1}$ )Sering terjadi kesalahan perhitungan skor nilai, $\left.{ }^{2}\right)$ Faktor like and dislike sangat tinggi, $\left.{ }^{3}\right)$ Terkadang pimpinan mengalami kesulitan pada saat menentukan pegawai yang tepat untuk diterima berdasarkan kriteria-kriteria yang telah ditentukan. Hal tersebut dapat mengakibatkan keputusan yang diambil pimpinan tidak tepat dan tidak potensial.

Berdasarkan permasalahan-permasalahan yang ada, maka dirasakan perlu dikembangkan Sistem Informasi yang dapat membantu pimpinan Politeknik Negeri Cilacap untuk menentukan hasil seleksi Pegawai baru di lingkungan Politeknik Negeri Cilacap berdasarkan kriteria-kriteria yang telah ditentukan. Untuk itu, penulis mengambil tema "Decision Support System (DSS) untuk membantu menentukan hasil seleksi pegawai di Politeknik Negeri Cilacap dengan menggunakan Metode Perbandingan Eksponensial (MPE)”. Dengan demikian keputusan yang diambil Pimpinan Politeknik Negeri Cilacap dalam menentukan diterima atau tidaknya pegawai tepat dan potensial.

\section{PENELITIAN YANG TERKAIT}

Penelitian yang terkait tentang Decision Support System atau Sistem Pendukung Keputusan sudah banyak yang dilakukan dengan metode dan penyelesaian yang berbedabeda. Penelitian yang terkait dengan judul sistem pendukung keputusan penentuan guru wali kelas pada SMP Negeri 19 Medan dengan menggunakan metode simple additive weighting. Pada penelitian tersebut, peneliti membuat Sistem Pendukung Keputusan untuk membantu sekolah dalam menentukan guru wali kelas yang layak dan kompeten sesuai dengan standar yang ditentukan. Sistem yang dikembangkan diharapkan dapat membantu menentukan penilaian kinerja guru dan mampu menentukan mana alternatif bobot terbaik berdasarkan rangking bobot tiap kriteria. Sistem penilaian menggunakan kriteria Profesionalisme, Pedagogik, Kepribadian, dan Rasa Sosial [6].

Penelitian lain yang terkait dengan judul sistem pendukung keputusan penentuan karyawan kontrak menjadi karyawan tetap menggunakan metode TOPSIS. Pada penelitian tersebut, peneliti membuat Sistem Pendukung Keputusan dengan menggunakan metode TOPSIS untuk menghitung hasil dalam penentuan karyawan kontrak menjadi karyawan tetap. Prosedur penentuan karyawan kontrak menjadi karyawan tetap, dimulai dari karyawan yang sudah melalui masa bekerja sebagai karyawan kontrak dan ingin bekerja sebagai karyawan tetap di PT. Gowa Motor Group. Kemudian akan dilakukan penentuan dengan penilaian dari aspek kinerja, loyalitas, kedisiplinan, tingkat pendidikan, dan pengalaman kerja [7].

Penelitian lain yang terkait dengan judul sistem pendukung keputusan pemilihan calon peserta olimpiade sains tingkat Kabupaten Langkat pada Madrasah Aliyah Negeri (MAN) 2 Tanjung Pura dengan menggunakan metode simple additive weighting (SAW). Pada penelitian tersebut, peneliti membuat Sistem Pendukung Keputusan yang dapat membantu pihak sekolah dalam menentukan siswa yang tepat dalam mengikuti olimpiade sains. Metode SAW dipilih karena mampu menyeleseksi alternatif terbaik dari sejumlah alternatif dalam pemilihan calon peserta olimpiade sains berdasarkan kriteria yang ditentukan. Kriteria-kriteria penilaian yang digunakan antara lain: peringkat rangking, nilai rata-rata fisika, nilai rata-rata kimia, nilai rata-rata matematika, dan nilai rata-rata kepribadian [8].

Penelitian lain yang terkait dengan judul model pengambilan keputusan untuk mengembalikan fungsi hutan pasca reklamasi lahan bekas timah dengan Analytical Hierarchy Proces. Penelitian ini menganalisa beberapa kriteria untuk meenentukan model pengambilan keputusan terbaik yang akan dilaksanakan di Pulau Bangka. Kriteriakriteria yang dianalisa adalah lokasi tambang, dampak lingkungan, dan teknologi perbaikan lahan. Alternatif alternatif yang akan dipilih untuk mengembalikan fungsi hutan di Pulau Bangka adalah agroforestri, ekowisata, silvopastura, dan silvofishery. Hasil penelitian memberikan informasi yang dapat digunakan untuk mendukung 
pengambilan keputusan dalam upaya memanfaatkan hutan produksi di wilayah lain yang juga mengalami lahan kritis akibat penambangan timah[9].

Penelitian lain yang terkait dengan judul sistem pendukung keputusan penentuan kelayakan calon tenaga kerja indonesia menggunakan metode Naive Bayes (Studi Kasus : PT. Karyatama Mitra Sejati Yogyakarta). Peneliti membuat Sistem Pendukung Keputusan penyeleksian calon tenaga kerja Indonesia dengan Metode Naive Bayes yang dapat membantu staff perusahaan dalam menentukan siapa yang layak diterima atau tidak. Kriteria penilaian yang digunakan dalam sistem ini antara lain: Pendidikan, Usia, Tinggi Badan, Berat badan, dan Nilai Tes [10].

Penelitian lain yang terkait dengan judul sistem pendukung keputusan pemilihan pengajar les privat untuk siswa lembaga bimbingan belajar dengan metode AHP (Studi Kasus LBB System Cerdas). Peneliti membuat Sistem Pendukung Keputusan yang dapat membantu lembaga dalam memilih pengajar agar lebih efisien dan efektif. Sistem yang dikembangkan menggunakan metode AHP. Kriteria yang menjadi pertimbangan dalam pemilihan pengajar ini meliputi jenis kelamin siswa, jumlah jam mengajar pengajar setiap minggu, jumlah siswa yang diajar pengajar, masa kerja pengajar, jurusan pengajar serta semester pengajar. Setiap kriteria dibandingkan dengan skala perbandingan agar mendapat nilai bobot untuk penilain pengajar [11].

Berbeda dengan penelitian-penelitian terkait yang pernah dilakukan sebelumnya. Pada penelitian ini, peneliti membuat Sistem Pendukung Keputusan (Decision Support System) untuk membantu menentukan hasil seleksi pegawai pada Politeknik Negeri Cilacap dengan menggunakan Metode Perbandingan Eksponensial (MPE). Metode tersebut dipilih karena cukup obyektif dalam membantu kerangka berfikir manusia dengan tingkat pengambilan keputusan yang kompleks. MPE dapat menghasilkan nilai alternatif yang perbedaannya lebih kontras, dimana nilai yang menggambarkan urutan prioritas menjadi besar sehingga mengakibatkan urutan prioritas alternative keputusan lebih nyata dan mempunyai keuntungan dalam mengurangi bias yang mungkin terjadi dalam analisis [12]. Disamping itu MPE merupakan salah satu metode dalam DSS yang tepat digunakan untuk menentukan urutan prioritas keputusan berdasarkan pada skor nilai total alternatif yang diberi bobot nilai pada masing-masing kriteria. Hasil perhitungan skor nilai total akan diurutkan berdasarkan peringkat nilai tertinggi sampai dengan nilai terendah dengan membandingkan antara objek satu dengan objek lainnya. Pengambil keputusan menggunakan nilai akhir tersebut untuk memilih alternatif yang terbaik, yaitu alternatif pilihan dengan dengan total skor terbesar [12].

Tujuan dari pengembangan sistem ini diharapkan dapat membantu pimpinan dalam mengambil keputusan yang tepat dan potensial dalam menentukan calon pegawai yang diterima menjadi Pegawai Politeknik Negeri Cilacap. Pegawai yang diseleksi terdiri dari dua jenis yaitu Tenaga Pendidik (Dosen) dan Tenaga Kependidikan (Non Dosen). Kriteria penilaian yang digunakan antara lain : Dokumen Administrasi dan hasil tes seleksi yang terdiri dari Tes Kemampuan Akademik (TKDA), Tes Bahasa Inggris (TBI), Tes Kompetensi Bidang Teori (TKBT), Tes Kompetensi Bidang Praktek (TKBP), dan Tes Wawancara (TW). Masing-masing kriteria diberikan bobot nilai.

\section{METODE PENELITIAN}

Penelitian dilakukan dengan beberapa tahapan, yaitu: 1) Melihat dan menganalisis proses seleksi pegawai di Politeknik Negeri Cilacap yang telah berjalan (existing condition); 2) Memetakan proses-proses yang ada; 3) Mencari permasalahan-permasalahan proses seleksi pegawai yang berjalan; 4) Mencari sumber permasalahan; dan 5) Merancang serta mengembangkan suatu sistem yang dapat dikembangkan untuk mereduksi atau mengeliminasi permasalahan yang ada.

\section{A. Bahan Penelitian}

Pada penelitian ini, bahan-bahan penelitian yang digunakan adalah sebagai berikut:

a. Data yang diperoleh dari studi analis yang telah dilakukan di Politeknik Negeri Cilacap baik melalui interview maupun pengamatan.

b. Data yang diperoleh dari studi literature mengenai Decision Support System dan Metode Perbandingan Eksponensial.

c. Alur proses seleksi pegawai yang berjalan di Politeknik Negeri Cilacap

d. Informasi mengenai pengembangan Sistem Informasi Decision Support System yang telah ada.

\section{B. Alat Penelitian}

Alat penelitian yang digunakan dalam penelitian ini adalah perangkat komputer yang memiliki spesifikasi cukup untuk menjalankan sistem operasi dan perangkat lunak yaitu Windows 7, Macromedia dreamweaver (software developer), xampp 1.7.3 (web server), dan Adobe Photoshop (software desain grafis).

\section{Tahapan Penelitian}

Dalam proses pengembangan Decision Support System ini, peneliti mengacu pada metode pengembangan perangkat lunak secara umum, yaitu metode pengembangan System Development Life Cycle (SDLC) model Waterfall. Metode ini berfungsi untuk mengembangkan, memelihara dan menggunakan sistem yang mencakup sejumlah fase atau tahapan sebagaimana ditunjukan pada Gbr. 1 .

Metode pengembangan model waterfall terdiri dari beberapa fase/tahapan. Metode tersebut akan digunakan dalam pengembangan sistem rancang bangun decision support system (dss) untuk membantu menentukan hasil seleksi pegawai Pada Politeknik Negeri Cilacap dengan menggunakan metode perbandingan eksponensial (MPE). 


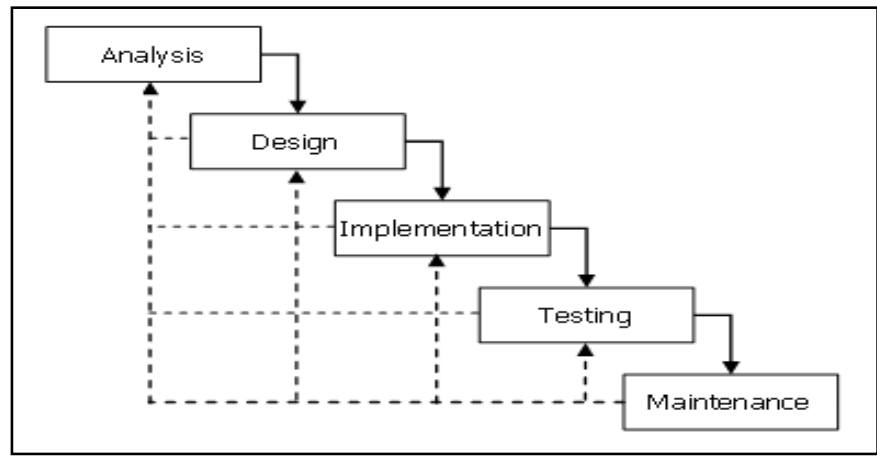

Gbr .1 Metode pengembangan Model Waterfall [13]

1) Tahap Analisis \& Requirement: Dalam tahap analisis dibagi menjadi beberapa langkah antara lain :

- Analisis permasalahan-permasalahan yang ada dan membuat studi kelayakan sistem yang akan dikembangkan.

- Analisis informasi yaitu mengenai informasi-informasi Politeknik Negeri Cilacap dan proses seleksi pegawai yang telah berjalan.

- Analisis user yaitu menentukan kebutuhan user, dalam arti mengidentifikasi user yang akan menggunakan sistem.

- Analisis teknologi yaitu menentukan kebutuhankebutuhan sistem baik dari software maupun hardware.

2) Tahap Desain: Pada tahap desain terdapat beberapa tahap, antara lain:

- Model development merupakan model yang akan digunakan sebagai arsitektur sistem. Model ini menggambarkan relationship (hubungan) dari sistem keseluruhan, antara semua fungsi dalam module yang terpisah, perubahan atau perpindahan data dari module dalam sistem.

- Desain database merupakan hubungan relasi antara Tabel dapat berupa normalisasi, dan menggambarkan secara detail masukan dan keluaran data.

3) Tahap Implementation: Hasil dari tahap implementation adalah berupa software Decision Support System.

4) Tahap Testing: Merupakan tahap pengujian sistem dan penyempurnaan sistem yang dikembangkan.

5) Tahap Maintenance: Pada tahap ini dilakukan perbaikan apabila terdapat kesalahan (error), meningkatkan kinerja dan kualitas aplikasi yang dikembangkan

\section{Perancangan Sistem}

Perancangan sistem yang akan dikembangkan digambarkan dalam flowchart seperti yang ditunjukan pada Gbr. 2.

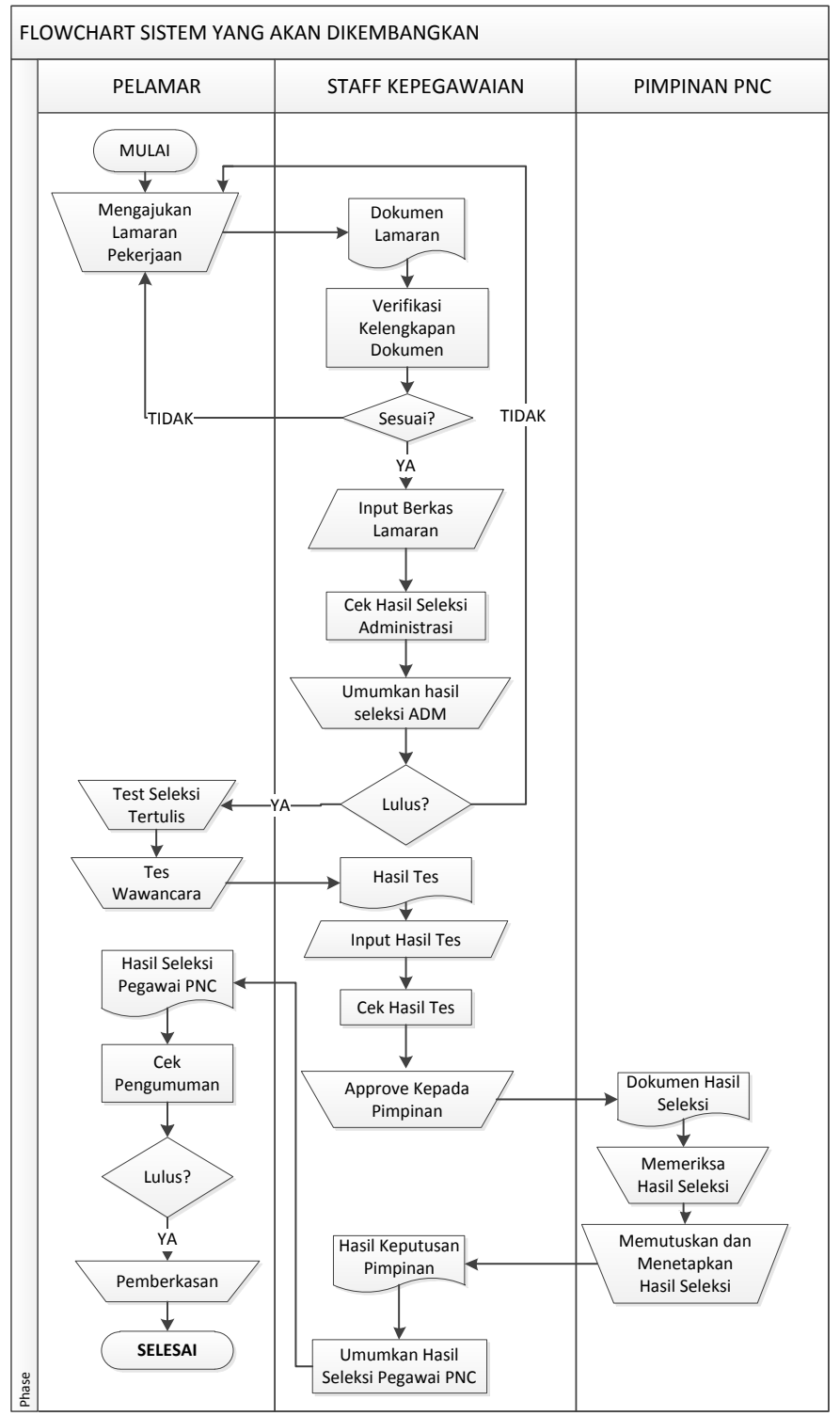

Gbr. 2 Flowchart analisis sistem yang akan dikembangkan

Gbr.2 menjelaskan analisis sistem yang akan dikembangkan dan menunjukan 3 aktor. Ketiga aktor tersebut memiliki peran masing-masing baik yang dilakukan secara manual maupun yang dilakukan dengan menggunakan sistem. Dalam sistem yang dikembangkan, aktor yang akan menggunakan sistem hanya staff kepegawaian Politeknik Negeri Cilacap saja, sedangkan kedua aktor lainnya berperan dengan sistem manual.

Flowchart pada Gbr. 2 dapat dijelaskan sebagai berikut :

- Dokumen lamaran yang diajukan oleh pelamar, diinputkan ke dalam sistem oleh staff kepegawaian,

- Kelengkapan dokumen administrasi akan dicek oleh sistem dan akan menghasilkan output Lulus atau Tidak.

- Bagi pelamar yang lulus seleksi administrasi, dapat melanjutkan tahap seleksi berikutnya yaitu seleksi tertulis berupa; Tes Kemampuan Dasar Akademik (TKDA), Tes Bahasa Inggris (TBI), Tes Kemampuan 
Bidang Teori (TKBT), Tes Kemampuan Bidang Praktek (TKBP), dan Tes Wawancara.

- Hasil seleksi Tes akan diinputkan dalam sistem

- Sistem akan secara otomatis melakukan perhitungan skor nilai sesuai dengan ketentuan yang telah ditetapkan dan mengurutkan hasilnya dimulai dari skor tertinggi sampai dengan skor terendah.

- Bagi peserta tes yang nilainya diatas nilai ambang batas (skor minimal), maka akan dinyatakan Lulus, sedangkan peserta tes yang nilainya dibawah nilai ambar batas (skor minimal), maka akan dinyatakan Tidak Lulus.

- Hasil seleksi tes akan disampaikan kepada pimpinan PNC, untuk menentukan diterima atau tidaknya.

Rancangan sistem yang akan dikembangkan juga digambar dengan menggunakan Context Diagram dan Data Flow Diagram (DFD) yang menjelaskan proses-proses yang dikembangkan dalam sistem. Salah satu manfaat DFD adalah memungkinkan penganalisis sistem memahami keterkaitan antara subsistem yang satu dengan subsistem yang lainnya[14].

\section{a) Context Diagram:}

Context diagram sistem yang dikembangkan ditunjukan pada Gbr. 3. Pada Gbr.3 menjelaskan contect diagram yang menggambarkan proses secara keseluruhan dalam sistem yang dikembangkan. Terdapat 2 (dua) aktor yang berperan dan mempergunakan sistem yaitu : Administrator dan Staff Kepegawaian Politeknik Negeri Cilacap.

Administrator memiliki otorization system dalam hal:

- Melakukan setting bobot nilai tes (TKDA, TBI, TKBT, TKBP, dan TW) sesuai ketentuan yang telah ditetapkan oleh Politeknik Negeri Cilacap.

- Melakukan setting nilai ambang batas (skor minimal) sesuai ketentuan yang telah ditetapkan oleh Politeknik Negeri Cilacap.

- Menginputkan daftar unit kerja yang ada di Politeknik Negeri Cilacap

- Menginputkan daftar Perguruan Tinggi di Indonesia sebagai list asal Perguruan Tinggi pelamar.

- Menginputkan standar kelulusan yang telah ditetapkan oleh Politeknik Negeri Cilacap

- Mengelola data user.

Staff Kepegawaian memiliki otorization system dalam hal:

- Menginputkan dokumen administrasi pelamar,

- Menginputkan Kompetensi Bidang Kompetensi dan Pengalaman Kerja Pelamar,

- Melakukan approve seleksi administrasi,

- Menginputkan skor hasil seleksi (TKDA, TBI, TKBT, TKBP, dan TW) kedalam sistem,

- Melakukan approve hasil seleksi (TKDA, TBI, TKBT, TKBP, dan TW) kedalam sistem.

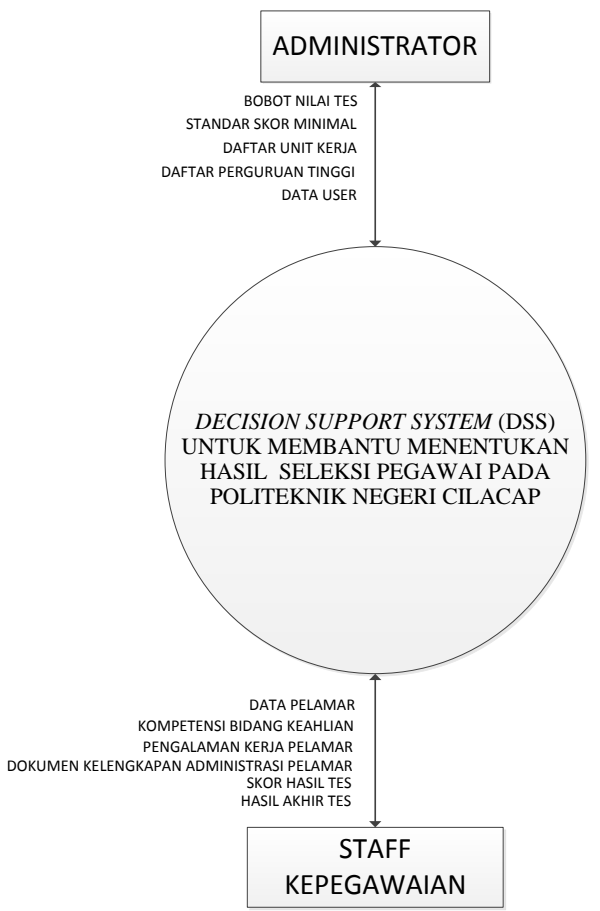

Gbr. 3 Context Diagram Sistem yang dikembangkan

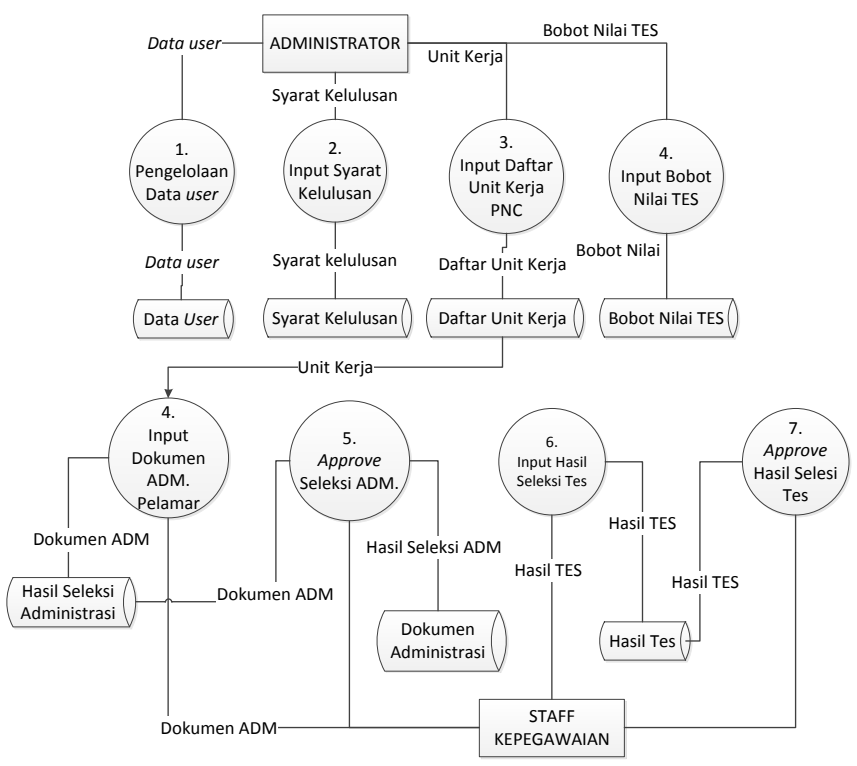

Gbr. 4 DFD Level 0

b) Data Flow Diagram (DFD) Level 0

Untuk menjelaskan fungsi-fungsi utama yang dikembangkan dalam sistem, perlu dibuat DFD Level 0 seperti yang ditunjukan pada Gbr. 4. Pada Gbr.4 menjelaskan DFD Level 0 sistem yang dikembangkan. Terdapat 2 (dua) aktor yang berperan atau menggunakan sistem. Pada gambar tersebut dijelaskan bahwa Administrator dan Staff Kepegawaian PNC memiliki tugas masing-masing. 
- Administrator

1) Mengelola data user

2) Input syarat kelulusan

3) Input daftar unit kerja PNC

- Input Bobot Nilai Tes yang terdiri dari Tes (TKDA, TBI, TKBT, TKBP, dan TW) baik untuk tenaga pendidik maupun tenaga kependidikan

- Staff Kepegawaian

1) Input Dokumen Administrasi Pelamar

2) Approve seleksi Administrasi

3) Input Hasil Tes (TKDA, TBI, TKBT, TKBP, dan TW)

4) Approve hasil Tes (TKDA, TBI, TKBT, TKBP, dan TW)

DFD Level 0 sebagaimana yang terlihat pada Gbr.4 dapat diturunkan lagi menjadi beberapa Level agar dapat menjelaskan proses secara lebih detail.

\section{c) DFD Level 1 Proses Input Syarat Kelulusan}

Berdasarkan Gbr.4 proses-proses yang telah dijelaskan pada gambar tersebut perlu diturunkan kepada level berikutnya, salah satunya adalah DFD Level 1 Proses Input Syarat Kelulusan seperti yang ditunjukan pada Gbr. 5.

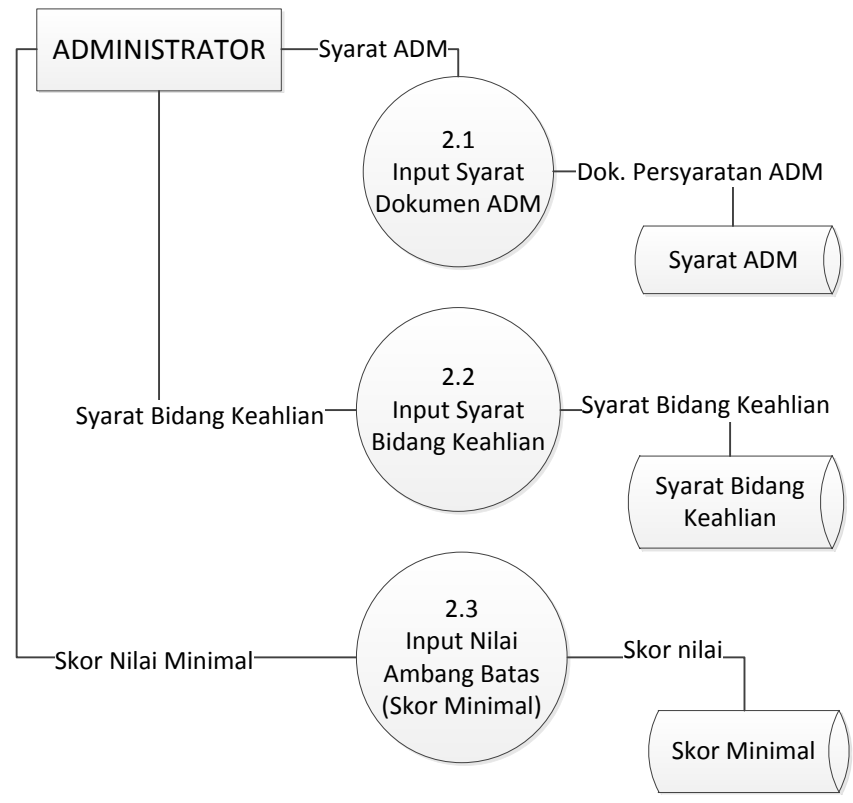

Gbr. 5 DFD Level 1 Proses Input Syarat Kelulusan

Gbr. 5 menjelaskan DFD Proses Input Syarat Kelulusan yang telah diturunkan menjadi Level 1. Pada gambar tersebut dijelaskan bahwa, dalam proses Input syarat kelulusan administrator melakukan tiga proses, yaitu :

1) Proses Input syarat Administrasi: Terdiri dari syarat pendidikan, syarat nilai (IPK) dan beberapa syarat lainnya

2) Proses Input Syarat Bidang Kompetensi: Terdiri dari syarat bidang Kompetensi yang harus dimiliki oleh pelamar terutama untuk tenaga Pendidik
3) Proses Input Ambang Batas (Skor minimal): Yaitu memasukan batas skor minimal hasil seleksi tes untuk dapat dinyatakan lulus atau tidak pasing grade tes seleksi.

\section{HASIL DAN PEMBAHASAN}

Hasil penelitian yang dilakukan adalah terciptanya sistem informasi yaitu Decision Support System untuk membantu menentukan hasil seleksi pegawai di Politeknik Negeri Cilacap dengan menggunakan Metode Perbandingan Eksponensial (MPE). Dalam menentukan hasil seleksi pegawai, sistem akan melakukan perhitungan berdasarkan kriteria-kriteria yang ditentukan dimana masing-masing kriteria diberi bobot nilai. Seleksi pegawai dibedakan dalam dua kategori, antara lain seleksi Tenaga Pendidik (Dosen) dan seleksi Tenaga Kependidikan (Non Dosen).

\section{A. Proses Pembobotan}

Terdapat perbedaan antara kedua kategori tersebut yaitu pada Seleksi pegawai Tenaga Pendidik (Dosen) menggunakan tahap seleksi Tes Kompetensi Bidang Praktek (TKBP) sedangan seleksi Tenaga Kependidikan tidak menggunakan tahap seleksi Tes Kompetensi Bidang Praktek (TKBP). Kriteria dan pembobotan nilai pada seleksi Tenaga Pendidik (Dosen) ditunjukan pada Tabel I dan Kriteria dan pembobotan nilai pada seleksi Tenaga Kependidikan ditunjukan pada Tabel II .

TABEL I

Kriteria Dan Pembobotan Nilai Pada Seleksi Tenaga Pendidik (DOSEN)

\begin{tabular}{|c|l|c|}
\hline No. & \multicolumn{1}{|c|}{ Kriteria } & Bobot Nilai \\
\hline 1. & $\begin{array}{l}\text { Tes Kemampuan Akademik } \\
(\text { TKDA) }\end{array}$ & $20 \%$ \\
\hline 2. & Tes Bahasa Inggris (TBI) & $20 \%$ \\
\hline 3. & $\begin{array}{l}\text { Tes Kompetensi Bidang Teori } \\
(\text { TKBT) }\end{array}$ & $20 \%$ \\
\hline 4. & $\begin{array}{l}\text { Tes Kompetensi Bidang Praktek } \\
(\text { TKBP) }\end{array}$ & $30 \%$ \\
\hline 5. & Tes Wawancara (TW) & $10 \%$ \\
\hline
\end{tabular}

TABEL II

Kriteria Dan Pembobotan Nilai Pada Seleksi Tenaga KePendidikan

\begin{tabular}{|c|l|c|}
\hline No. & \multicolumn{1}{|c|}{ Kriteria } & Bobot Nilai \\
\hline 1. & $\begin{array}{l}\text { Tes Kemampuan Akademik } \\
(\text { TKDA) }\end{array}$ & $30 \%$ \\
\hline 2. & Tes Bahasa Inggris (TBI) & $30 \%$ \\
\hline 3. & $\begin{array}{l}\text { Tes Kemampuan Bidang Teori } \\
(\text { TKBT) }\end{array}$ & $30 \%$ \\
\hline 4. & Tes Wawancara (TW) & $10 \%$ \\
\hline
\end{tabular}

Perhitungan skor nilai alternatif dilakukan dengan menggunakan Metode Perbandingan Eksponensial (MPE). Metode Perbandingan Exponensial adalah salah satu metode dari Decision Suport System (DSS) yang digunakan untuk menentukan urutan prioritas alternatif keputusan dengan kriteria jamak [15]. Dalam menggunakan Metode 
Perbandingan Eksponensial, ada beberapa tahapan yang harus dilakukan, yaitu:

- Menyusun alternatif-alternatif keputusan yang akan dipilih;

- Menentukan kriteria atau perbandingan kriteria keputusan yang penting untuk dievaluasi;

- Menentukan tingkat kepentingan dari setiap kriteria keputusan atau pertimbangan kriteria;

- elakukan penilaian terhadap semua alternatif pada setiap kriteria;

- Menghitung skor atau nilai setiap alternatif;

- Menentukan urutan prioritas keputusan didasarkan pada skor atau nilai total masing-masing alternatif.

Formulasi perhitungan skor untuk setiap alternatif dalam Metode Perbandingan Eksponensial adalah sebagai berikut :

Total nilai $(\mathrm{TNi})=\sum_{\mathrm{j}=1}^{\mathrm{m}}\left(\mathrm{RK}_{\mathrm{ij}}\right) \mathrm{TKK}_{\mathrm{j}}$

Keterangan :

$\mathrm{TNi}=$ Total nilai alternatif $\mathrm{ke}-\mathrm{i}$

RK ij = derajat kepentingan relatif kriteria ke-j pada pilihan keputusan $\mathrm{i}$

$\mathrm{TKK} \mathrm{j}=$ derajat kepentingan kritera keputusan ke-j; $\mathrm{TKKj}>0$; bulat

n $\quad=$ jumlah pilihan keputusan

$\mathrm{m} \quad=$ jumlah kriteria keputusan

Untuk memberikan gambaran perhitungan skor pada setiap alternatif, dapat disimulasikan perhitungan berdasarkan data yang ditunjukan pada Tabel III. Simulasi perhitungan skor nilai alternatif sebagai berikut :

Nilai Alternatif $[1]=\begin{aligned} & 70 * 20 / 100+60 * 20 / 100+80 * 20 / 100+ \\ & 75 * 30 / 100+80 * 10 / 100=72,5\end{aligned}$

Nilai Alternatif [2] $=65 * 20 / 100+70 * 20 / 100+60 * 20 / 100+$ $70 * 30 / 100+75 * 10 / 100=67,5$

Nilai Alternatif [5] $=55 * 20 / 100+60 * 20 / 100+60 * 20 / 100+$ $55 * 30 / 100+70 * 10 / 100=58,5$

Berdasarkan simulasi perhitungan skor nilai alternatif diatas, maka diperoleh hasil perhitungan yang telah diurutkan berdasarkan peringkat tertinggi. Nilai Alternatif hasil perhitungan ditunjukan pada Tabel IV. Tahap selanjutnya, skor nilai alternatif akan disesuaikan dengan Nilai Ambang Batas (NAB) yang telah ditentukan. Nilai Ambang Batas adalah nilai batas minimal (passing grade) yang digunakan untuk menentukan Lulus atau Tidak Lulus yang dibuat persamaan sebagai berikut.

$$
\begin{array}{ll}
\text { Jika } \mathrm{TNi} \geq \mathrm{NAB} & =\text { LULUS } \\
\text { Jika TNi }<\mathrm{NAB} & =\text { TIDAK LULUS }
\end{array}
$$

Apabila NAB ditentukan sebesar 70, maka sistem akan menentukan hasil akhir seleksi pegawai yang ditunjukan pada Tabel V. Dalam sistem yang dikembangkan terdapat 2 (dua) level user, yaitu : Administrator dan Petugas Kepegawaian.

TABEL III

SiMUlasi DATA HASIL TES SELEKSI

\begin{tabular}{|c|l|c|c|c|c|c|}
\hline \multirow{2}{*}{ No. } & \multirow{2}{*}{ Nama } & \multicolumn{5}{|c|}{ Nilai } \\
\cline { 3 - 7 } & & TKDA & TBI & TKBT & TKBP & TW \\
\hline 1. & Andi & 70 & 60 & 80 & 75 & 80 \\
\hline 2. & Iwan & 65 & 70 & 60 & 70 & 75 \\
\hline 3. & Budi & 60 & 65 & 75 & 78 & 75 \\
\hline 4. & Ita & 70 & 75 & 55 & 60 & 70 \\
\hline 5. & Sinta & 55 & 60 & 60 & 55 & 70 \\
\hline
\end{tabular}

TABEL IV

NILAI ALTERNATIF

\begin{tabular}{|c|l|c|c|}
\hline No. & Nama & Nilai Alternatif & Urutan \\
\hline 1. & Andi & 72,5 & Peringkat 1 \\
\hline 2. & Budi & 70,9 & Peringkat 2 \\
\hline 3. & Iwan & 67,5 & Peringkat 3 \\
\hline 4. & Ita & 65 & Peringkat 4 \\
\hline 5. & Sinta & 58,5 & Peringkat 5 \\
\hline
\end{tabular}

TABEL V

HASIL AKHIR SELEKSI PEGAWAI

\begin{tabular}{|c|l|c|c|}
\hline No. & Nama & Nilai Alternatif & Keterangan \\
\hline 1. & Andi & 72,5 & LULUS \\
\hline 2. & Budi & 70,9 & LULUS \\
\hline 3. & Iwan & 67,5 & TIDAK LULUS \\
\hline 4. & Ita & 65 & TIDAK LULUS \\
\hline 5. & Sinta & 58,5 & TIDAK LULUS \\
\hline
\end{tabular}

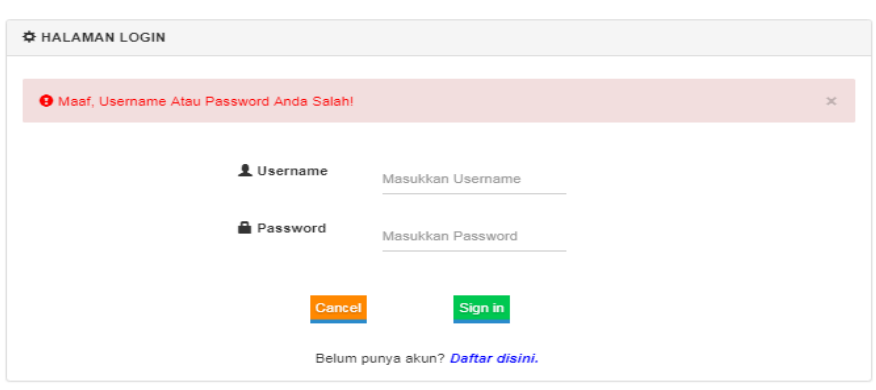

Gbr. 6 Tampilan Login User

\section{B. Implementasi Sistem}

1) Halaman Utama Level Administrator

Halaman Administrator berfungsi untuk melakukan setting atau pengaturan terhadap standar kelulusan seleksi pegawai pada Politeknik Negeri Cilacap. Untuk dapat mengakses sistem, maka user harus login terlebih dahulu seperti yang ditunjukan pada Gbr. 6 .

\section{2) Halaman Utama Level Petugas Kepegawaian}

Decision Support System yang dikembangkan terdapat beberapa konsep atau fungsi utama, antara lain : 
- Menentukan standar persyaratan khusus

- Menentukan bobot masing-masing komponen penilaian

- Menentukan Skor Nilai Ambang Batas (NAB)

- Menentukan hasil seleksi administrasi

- Menentukan hasil tes tertulis, praktek, dan wawancara

- Menentukan hasil akhir seleksi pegawai

\section{Penentuan Fungsi}

1) Fungsi menentukan persyaratan khusus

Persyaratan khusus merupakan salah satu kunci utama dalam proses seleksi pegawai. Dalam sistem yang dikembangkan fungsi menentukan persyaratan khusus ditunjukan pada Gbr. 7.

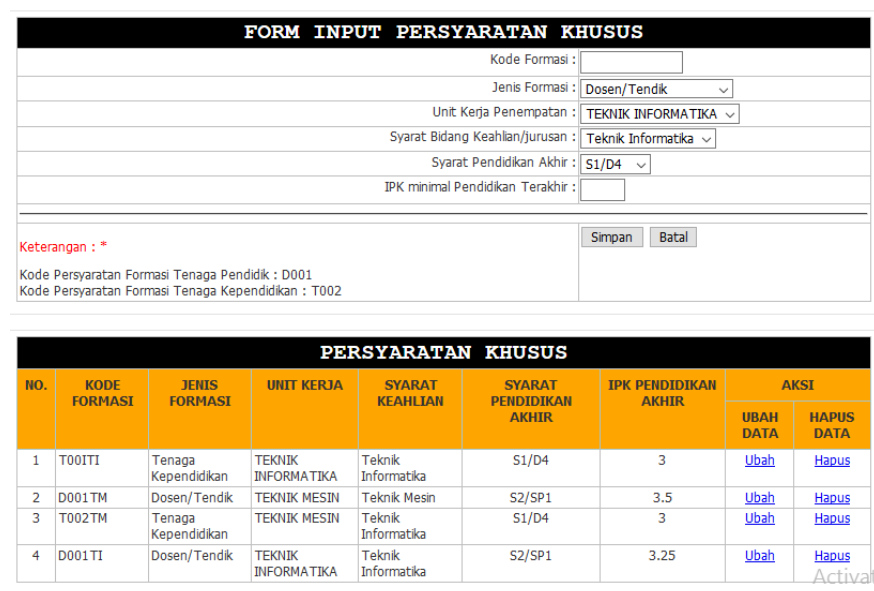

Gbr. 7 Tampilan setting persyaratan khusus
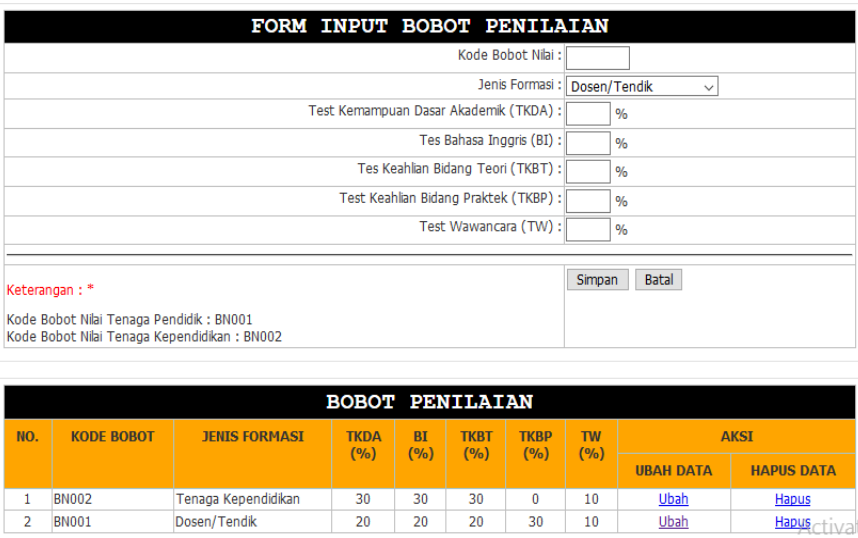

Gbr. 8 Tampilan Bobot Penilaian

Gbr.7 menunjukan proses setting persyaratan khusus untuk seleksi pegawai pada Politeknik Negeri Cilacap. Standar kelulusan (persyaratan khusus) bagi tenaga pendidik (Dosen) maupun tenaga kependidikan disesuaikan dengan kebutuhan dari masing-masing unti kerja.

\section{2) Fungsi menentukan bobot masing - masing komponen} penilaian

Dalam sistem yang dikembangkan, untuk menentukan bobot masing-masing komponen penilaian seleksi pegawai pada Politeknik Negeri Cilacap ditunjukan pada Gbr. 8. Pada Gbr. 8 menunjukan proses penentuan Bobot Penilaian seleksi pegawai pada Politeknik Negeri Cilacap. Seperti yang dijelaskan sebelumnya bahwa, sistem yang dikembangkan adalah untuk membantu pengambilan keputusan dalam seleksi pegawai Tenaga Pendidik (Dosen) dan Tenaga Kependidikan (Non Dosen). Apabila pelamar dinyatakan lolos administrasi, maka pelamar dapat mengikuti seleksi tahap berikutnya. Terdapat beberapa komponen penilaian pada tahap seleksi pegawai Politeknik Negeri Cilacap, antara lain :

- Tes Kompetensi Dasar (TKDA)

- Tes Bahasa Inggris (TBI)

- Tes Kompetensi Bidang Teori (TKBT)

- Tes Kompetensi Bidang Praktek (TKBP)

- Tes Wawancara

Masing-masing nilai bobot ditentukan berdasarkan kebutuhan Politeknik Negeri Cilacap. Namun, dalam sistem yang dikembangkan terdapat perbedaan yang mendasar antara bobot penilaian seleksi pegawai Tenaga Pendidikan (Dosen) dan bobo penilaian seleksi pegawai Tenaga Kependidikan (Non Dosen) yaitu, pada tahap seleksi Tenaga Pendidik (Dosen) terdapat komponen penilaian Tes Kompetensi Bidang Praktek (TKBP), sedangkan pada tahap seleksi Tenaga Kependidikan (Non Dosen) tidak terdapat komponen penilaian Tes Kompetensi Bidang Praktek (TKBP).

\section{3) Fungsi menentukan Skor Nilai Ambang Batas (NAB)}

Dalam sistem yang dikembangkan, fungsi menentukan skor akhir minimal dapat ditunjukan pada Gbr. 9.

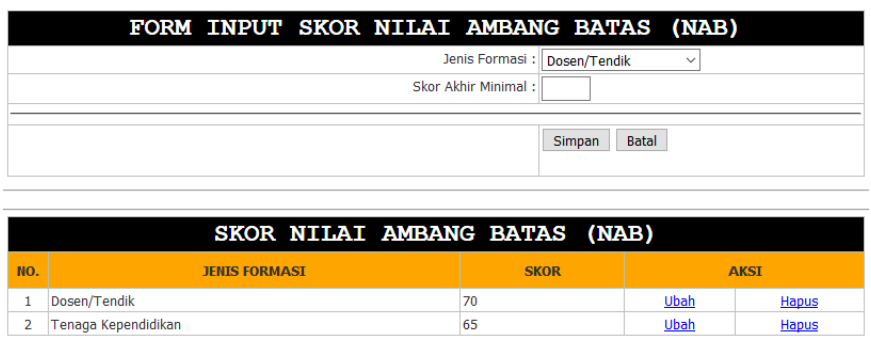

Gbr.9 Tampilan menentukan skor Nilai Ambang Batas (NAB)

Gbr.9 menunjukan fungsi menentukan Skor Akhir Minimal yang digunakan untuk menentukan standar batas minimal kelulusan. Standar minimal kelulusan dapat ditentukan sesuai dengan kebutuhan Politeknik Negeri Cilacap baik untuk Tenaga Pendidik (Dosen) maupun Tenaga Kependidikan (Non Dosen).

\section{4) Fungsi menentukan hasil seleksi administrasi}

Dalam sistem yang dikembangkan, sistem akan melakukan selesksi secara otomastis berdasarkan persyaratan yang telah ditentukan. Berdasarkan simulasi seleksi administrasi, terdapat beberapa pelamar yang lolos seleksi administrasi sebagaimana ditunjukan pada Gbr. 10 . 


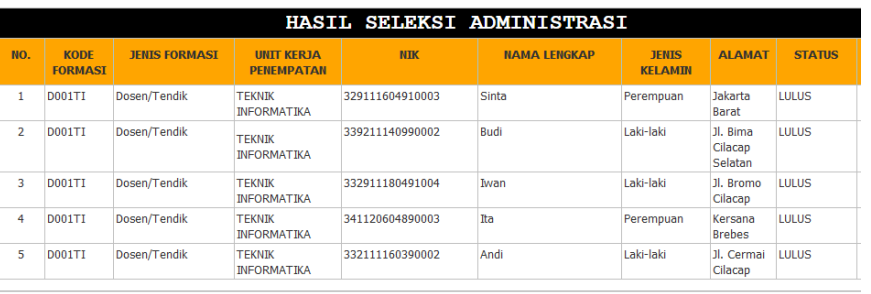

Gbr. 10 Tampilan hasil seleksi administrasi

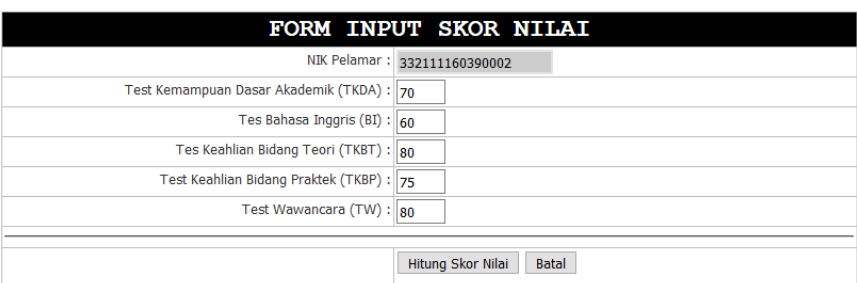

Gbr.11 Tampilan pengisian skor nilai alternatif hasil tes

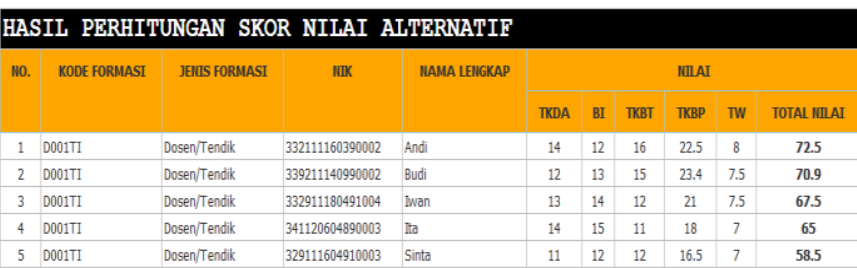

Gbr. 12 Tampilan perhitungan skor nilai alternatif

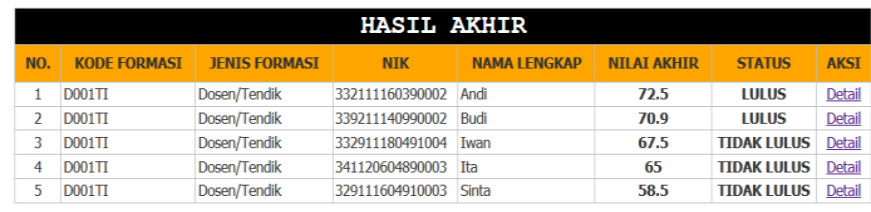

Gbr.13 Tampilan Hasil Akhir seleksi pegawai PNC

Bagi pelamar yang lolos seleksi administrasi dapat melanjutkan tahap seleksi berikutnya yaitu tahap Tes Kompetensi Dasar, Tes Bahasai Inggris, Tes Kompetensi Bidang Teori, Tes Kompetensi Bidang Praktek, dan Tes Wawancara.

\section{5) Fungsi menentukan Skor nilai alternatif Hasil Tes}

Dalam sistem yang dikembangkan, untuk dapat melihat hasil tes TKB, maka user harus menginputkan skor nilai pada masing-masing komponen penilaian seperti yang ditunjukan pada Gbr. 11. Pada Gbr.11 menunjukan proses pengisian skor nilai alternatif pada masing-masing komponen penilaian. Setalah dilakukan pengisian skor, maka user dapat melakukan perhitungan skor dengan meng-klik tombol hitung skor nilai. Setelah dihitung dengan menggunakan rumus Metode Perbandingan Eksponensial (MPE), maka diperolah hasil skor nilai alternatif yang ditunjukan pada Gbr. 12. Pada Gbr. 12 menunjukan hasil perhitungan skor nilai alternatif yang telah dilakukan oleh sistem secara otomatis. Masing-masing komponen penilaian telah dihitung berdasarkan bobot penilaian yang telah ditentukan.

6) Fungsi menentukan hasil akhir seleksi pegawai

Hasil perhitungan skor nilai alternatif seperti yang ditunjukan pada Gmb. 12, akan dikomparasikan atau disesuaikan dengan Nilai Ambang Batas (NAB) yang telah ditentukan. Apabila disimulasikan $\mathrm{NAB}=70$, maka sistem akan melakukan pengecekan apakah pelamar dinyatakan Lulus atau dinyatakan Tidak Lulus. Hasil pengecekan ditunjukan pada Gbr. 13. Pada Gbr.13 menunjukan hasil akhir proses seleksi pegawai yang dapat dinyatakan LULUS atau TIDAK LULUS.

\section{Pengujian Sistem}

TABEL VI

SKENARIO PENGUJIAN SISTEM BLACK BOX TESTING

\begin{tabular}{|c|c|c|c|}
\hline \multicolumn{4}{|c|}{ Kasus dan Hasil Uji } \\
\hline $\begin{array}{c}\text { Data } \\
\text { Masukan }\end{array}$ & $\begin{array}{c}\text { Yang } \\
\text { Diharapkan }\end{array}$ & Pengamatan & Status \\
\hline \multirow{7}{*}{$\begin{array}{l}\text { Dokuman } \\
\text { ADM. } \\
\text { Skor nilai } \\
\text { (TKDA), } \\
\text { (TBI), } \\
\text { (TKBT), } \\
\text { (TKBP), } \\
\text { (TW) }\end{array}$} & $\begin{array}{l}\text { Dapat } \\
\text { melakukan } \\
\text { seleksi } \\
\text { administrasi }\end{array}$ & $\begin{array}{l}\text { Dapat } \\
\text { melakukan } \\
\text { seleksi } \\
\text { administrasi }\end{array}$ & $\begin{array}{l}\text { [x] berhasil } \\
{[\text { ] gagal }}\end{array}$ \\
\hline & $\begin{array}{l}\text { Dapat melihat } \\
\text { hasil seleksi } \\
\text { administrasi }\end{array}$ & $\begin{array}{l}\text { Dapat melihat } \\
\text { hasil seleksi } \\
\text { administrasi }\end{array}$ & $\begin{array}{l}\text { [x] berhasil } \\
{[\text { ] gagal }}\end{array}$ \\
\hline & $\begin{array}{l}\text { Dapat } \\
\text { menginputkan } \\
\text { skor nilai } \\
\text { TKDA, TBI, } \\
\text { TKBT, TKBP, } \\
\text { dan TW. }\end{array}$ & $\begin{array}{l}\text { Dapat } \\
\text { menginputkan } \\
\text { skor nilai } \\
\text { TKDA, TBI, } \\
\text { TKBT, TKBP, } \\
\text { dan TW. }\end{array}$ & $\begin{array}{l}\text { [x] berhasil } \\
{[\text { ] gagal }}\end{array}$ \\
\hline & $\begin{array}{l}\text { Dapat } \\
\text { melakukan } \\
\text { perhitungan } \\
\text { nilai alternatif } \\
\text { TKDA, TBI, } \\
\text { TKBT, TKBP, } \\
\text { dan TW }\end{array}$ & $\begin{array}{l}\text { Dapat } \\
\text { melakukan } \\
\text { perhitungan } \\
\text { nilai alternatif } \\
\text { TKDA, TBI, } \\
\text { TKBT, TKBP, } \\
\text { dan TW }\end{array}$ & $\begin{array}{l}\text { [x] berhasil } \\
{[\text { ] gagal }}\end{array}$ \\
\hline & $\begin{array}{l}\text { Dapat melihat } \\
\text { hasil } \\
\text { perhitungan } \\
\text { nilai alternatif }\end{array}$ & $\begin{array}{l}\text { Dapat melihat } \\
\text { hasil } \\
\text { perhitungan } \\
\text { nilai alternatif }\end{array}$ & $\begin{array}{l}\text { [x] berhasil } \\
{[\text { ] gagal }}\end{array}$ \\
\hline & $\begin{array}{l}\text { Dapat } \\
\text { mengurutkan } \\
\text { total skor nilai } \\
\text { alternatif } \\
\text { berdasarkan } \\
\text { peringkat }\end{array}$ & $\begin{array}{l}\text { Dapat } \\
\text { mengurutkan } \\
\text { total skor nilai } \\
\text { alternatif } \\
\text { berdasarkan } \\
\text { peringkat }\end{array}$ & $\begin{array}{l}{[\mathrm{x}] \text { berhasil }} \\
{[\text { ] gagal }}\end{array}$ \\
\hline & $\begin{array}{l}\text { Dapat } \\
\text { menentukan } \\
\text { hasil akhir } \\
\text { seleksi } \\
\text { (Lulus/Tidak } \\
\text { Lulus) }\end{array}$ & $\begin{array}{l}\text { Dapat } \\
\text { menentukan } \\
\text { hasil akhir } \\
\text { seleksi } \\
\text { (Lulus/Tidak } \\
\text { Lulus) }\end{array}$ & $\begin{array}{l}{[\mathrm{x}] \text { berhasil }} \\
{[\mathrm{]} \text { gagal }}\end{array}$ \\
\hline
\end{tabular}


Untuk dapat melihat fungsi sistem berjalan dengan baik dan sesuai dengan perencanaan dan kebutuhan fungsional, maka perlu dilakukan pengujian sistem. Pengujian sistem dilakukan dengan menggunakan metode pengujian black box testing. Metode black box testing merupakan pengujian yang dilakukan hanya mengamati hasil eksekusi melalui data uji dan memeriksa fungsional dari perangkat lunak. Skenario hasil pengujian sistem ditunjukan pada Tabel VI.

Hasil pengujian perhitungan dengan MPE juga dapat diketahui dengan membandingkan hasil perhitungan nilai alternatif terhadap 5 (lima) peserta tes yang dilakukan secara manual seperti yang ditunjukan pada Tabel $\mathrm{V}$ dengan hasil perhitungan alternatif menggunakan sistem seperti yang ditunjukan pada Gbr.13. Berdasarkan hasil perhitungan tersebut, diperoleh hasil yang sama untuk setiap alternatif, dimana peserta tes atas nama Andi mendapatkan skor nilai tertinggi dengan nilai akhir $\mathbf{7 2 , 5}$ dan peserta tes atas nama Sinta mendapatkan skor nilai terendah dengan nilai akhir $\mathbf{5 8 , 5}$.

\section{KESIMPULAN}

Berdasarkan hasil penelitian yang telah dilakukan dengan mengembangakan Decision Support System (DSS) untuk membantu menentukan hasil seleksi pegawai pada Politeknik Negeri Cilacap, maka dapat dibuat kesimpulan bahwa Decision Support System (DSS) yang dikembangkan dapat membantu Pimpinan Politeknik Negeri Cilacap dalam mengambil keputusan yang tepat dan potensial untuk memilih calon pegawai yang diterima. Perhitungan skor nilai alternatif dalam proses seleksi pegawai pada Politeknik Negeri Cilacap dapat dilakukan dengan menggunakan Metode Perbandingan Eksponensial dengan menentukan kriteria-kriteria tertentu yang masing-masing diberi bobot nilai. Hasil perhitungan nilai alternatif dapat ditampilkan secara berurut (sorting) berdasarkan peringkat tertinggi. Proses seleksi dokumen administrasi dapat dilakukan dengan menggunakan DSS berdasarkan persyaratan-persyaratan yang telah ditentukan. Dengan demikian validasi seleksi administrasi lebih terjamin dan dapat terhindar dari faktor like and dislike. Berdasarkan hasil pengujian yang telah dilakukan, sistem dapat berjalan dan berfungsi sesuai dengan kebutuhun fungsional, sehingga dapat membantu menentukan hasil seleksi pegawai pada Politeknik Negeri Cilacap. Hasil perhitungan skor nilai alternatif yang dilakukan secara manual dan perhitungan skor nilai alternatif menggunakan sistem menunjukan hasil yang sama diantara keduanya.

Saran yang dapat dibuat untuk pengembangan sistem dan penelitian selanjutnya adalah perlu pegembangan sistem lebih lanjut agar pendaftaran seleksi pegawai Politeknik Negeri Cilacap dapat dilakukan secara online, sehingga reqruitment pegawai Politeknik Negeri Cilacap menjadi lebih luas lagi. Apabila sistem dijalankan secara online, maka sistem keamanan (security system) perlu dikembangkan lagi, agar data-data dapat lebih terjamin dan akurat.

\section{DAFTAR PUSTAKA}

[1] D. Nurlaila, D. Supriyadi, and E. A. Amalia, "Penerapan Metode Analytic Network Process ( ANP) Untuk Pendukung Keputusan Pemilihan Tema Tugas Akhir," J. Inform. Pengemb. IT, vol. 02, no. 02, pp. 63-68, 2017.

[2] Y. A. Pranoto, M. A. Muslim, and R. N. Hasanah, "Rancang Bangun dan Analisis Decision Support System Menggunakan Metode Analytical Hierarchy Process untuk Penilaian Kinerja Karyawan," $J$. EECCIS, vol. 7, no. 1, p. pp-91, 2013.

[3] T. S. Jaya and D. Sahlinal, "Perancangan Kantor Digital Berbasis Framework dengan Metode Waterfall pada Politeknik Negeri Lampung," J. Inform. Pengemb. IT, vol. 02, no. 02, pp. 14-17, 2017.

[4] I. Afriliana, E. Budihartono, and A. Maulana, "Pengukuran Kinerja Dosen Menggunakan Metode Adaptive Neuro Fuzzy Inference System ( ANFIS )," J. Inform. Pengemb. IT, vol. 02, no. 02, pp. 109-112, 2017.

[5] N. Aristi and H. Hafiar, "Analisis Beban Kerja Tenaga Pendidik Dan Kependidikan Di Fakultas Y Universitas X," J. Kaji. Komun., vol. 2/1, pp. 53-60, 2014.

[6] P. S. Hasugian, H. D. Hutahaean, and H. T. Sihotang, "Sistem Pendukung Keputusan Penentuan Guru Wali Kelas Pada SMP Negeri 19 Medan Dengan Menggunakan Metode Simple Additive Weighting," J. Inform. Pelita Nusant., vol. 2, no. 1, pp. 32-39, 2017.

[7] S. Mallu, "Sistem Pendukung Keputusan penentuan karyawan kontrak menjadi karyawan tetap menggunakan metode topsis," J. Ilm. Teknol. Inf. Terap., vol. I, no. 2, pp. 36-42, 2015.

[8] H. Situmorang, "Olimpiade Sains Tingkat Kabupaten Langkat Pada Madrasah Aliyah Negeri ( Man ) 2 Tanjung Pura Denganmenggunakan Metode Simple Additive Weighting ( SAW )," Si, vol. IV, no. 2, pp. 24-30, 2015.

[9] H. Magdalena, "Model Pengambilan Keputusan Untuk Mengembalikan Fungsi Hutan Pasca Reklamasi Lahan Bekas Timah dengan Analytical Hierarchy Process," J. Inform. Pengemb. IT, vol. 02, no. 02, pp. 27-35, 2017.

[10] H. Wasiati and D. Wijayanti, "Sistem Pendukung Keputusan Penentuan Kelayakan Calon Tenaga Kerja Indonesia Menggunakan Metode Naive Bayes," Wasiati, Hera Wijayanti, Dwi, vol. 3, no. 2, p. $2,2014$.

[11] L. Kristiyanti, A. Sugiharto, and H. A. W, "Sistem Pendukung Keputusan Pemilihan Pengajar Les Privat Untuk Siswa Lembaga Bimbingan Belajar Dengan Metode AHP (Studi Kasus LBB System Cerdas)," J. Masy. Inform., vol. 4, no. 7, pp. 39-47, 2011.

[12] J. Ferry, "Sistem Pendukung Keputusan untuk Menentukan Prioritas Calon Pejabat Kepala Biro Dengan Menggunakan Metode Perbandingan Eksponensial ( MPE ) ( Studi Kasus : Sekretariat Daerah Provinsi Riau )," 2011.

[13] Y. Bassil, "A Simulation Model for the Waterfall Software Development Life Cycle," Int. J. Eng. Technol., vol. 2, no. 5, pp. 2049-3444, 2012.

[14] R. Afyenni, "Perancangan Data Flow Diagram untuk Sistem Informasi Sekolah (Studi Kasus Pada SMA Pembangunan Laboratorium UNP)," Teknoif, vol. 2, no. 1, pp. 35-39, 2014.

[15] Y. Nurhayati, "Implementasi Metode Perbandingan Eskponensial Dalam Penentuan Asisten Laboratorium (Studi Kasus: Di Lab FKOM UNIKU)," J. Nuansa Inform., vol. 10, pp. 1-10, 2014. 